NBER WORKING PAPER SERIES

\title{
THEORY, GENERAL EQUILIBRIUM AND POLITICAL ECONOMY IN DEVELOPMENT ECONOMICS
}

\author{
Daron Acemoglu \\ Working Paper 15944 \\ http://www.nber.org/papers/w15944 \\ NATIONAL BUREAU OF ECONOMIC RESEARCH \\ 1050 Massachusetts Avenue \\ Cambridge, MA 02138 \\ April 2010
}

The views expressed herein are those of the author and do not necessarily reflect the views of the National Bureau of Economic Research.

NBER working papers are circulated for discussion and comment purposes. They have not been peerreviewed or been subject to the review by the NBER Board of Directors that accompanies official NBER publications.

(C) 2010 by Daron Acemoglu. All rights reserved. Short sections of text, not to exceed two paragraphs, may be quoted without explicit permission provided that full credit, including (C) notice, is given to the source. 
Theory, General Equilibrium and Political Economy in Development Economics

Daron Acemoglu

NBER Working Paper No. 15944

April 2010

JEL No. B41,D50,O10,O12,P48

\begin{abstract}
$\underline{\text { ABSTRACT }}$
I discuss the role of economic theory in empirical work in development economics with special emphasis on general equilibrium and political economy considerations. I argue that economic theory plays (should play) a central role in formulating models, estimates of which can be used for counterfactual and policy analysis. I discuss why counterfactual analysis based on microdata that ignores general equilibrium and political economy issues may lead to misleading conclusions. I illustrate the main arguments using examples from recent work in development economics and political economy.
\end{abstract}

Daron Acemoglu

Department of Economics

MIT, E52-380B

50 Memorial Drive

Cambridge, MA 02142-1347

and CIFAR

and also NBER

daron@mit.edu 
Development economics investigates the causes of poverty and low incomes around the world and seeks to make progress in designing policies that could help individuals, regions, and countries to achieve greater economic prosperity. Economic theory plays a crucial role in this endeavor, not only because it helps us focus on the most important economic mechanisms, but also because it provides guidance on the external validity of econometric estimates, meaning that it clarifies how we can learn from specific empirical exercises about the effects of similar shocks and policies in different circumstances and when implemented on different scales.

General equilibrium and political economy issues often create challenges for this type of external validity. General equilibrium refers to factors that become important when we conduct (or ask questions involving) counterfactuals in which large changes are contemplated. The difficulty lies in the fact that such counterfactuals will induce changes in factor prices and technology which we hold fixed in partial equilibrium analysis and create different composition effects than in partial equilibrium. Political economy refers to the fact that the feasible set of interventions is often determined by political factors and large counterfactuals will induce political responses from various actors and interest groups. General equilibrium and political economy considerations are important because partial equilibrium estimates that ignore responses from both sources will not give the appropriate answer to counterfactual exercises.

In this essay, I first explain why it is important to think of external validity in policy analysis, particularly in development economics, and the role of economic theory in this exercise. I then illustrate the importance of general equilibrium reasoning in several major problems in development economics. Finally, I argue that political economy considerations have to be central to any investigation of development problems and that inferences that ignore political economy can go wrong. The online appendix includes a discussion of some additional issues that arise in the context of using theory in guiding estimation.

\section{Why Development Economics Needs Theory}

There is no general agreement on whether we should use economic theory for formulating and then subsequently attempting to estimate "structural parameters". I argue that the answer is largely "yes" because otherwise econometric estimates would lack external validity, in which case they can neither inform us about whether a particular model or theory is a useful approximation to reality, nor would they be useful in providing us guidance on what the effects of similar shocks and policies would be in different circumstances or if implemented in different scales. I therefore define structural parameters as those that provide external validity and 
would thus be useful in testing theories or in policy analysis beyond the specific environment and sample from which they are derived. ${ }^{1}$ External validity becomes a particularly challenging task in the presence of general equilibrium and political economy considerations, and a major role of economic theory is in helping us overcome these problems or at the very least alerting us to their importance.

To illustrate these points, consider the relationship between the cost of schooling and schooling decisions. We can describe this relationship purely as a descriptive one, focusing on a sample and looking at the correlation or the ordinary least squares relationship between these two variables. For example, we could specify the following "reduced-form" relationship:

$$
\log \left(s_{i}\right)=\mathbf{X}_{i}^{\prime} \boldsymbol{\beta}-\alpha \log \left(c_{i}\right)+\varepsilon_{i}
$$

where $i$ denotes an individual in the sample, $s_{i}$ is years of schooling, $c_{i}$ denotes the cost of schooling to the individual resulting, for example, from forgone earnings and actual costs of attending schools, $\mathbf{X}_{i}$ is a vector of characteristics of this individual for which we may wish to control, and $\boldsymbol{\beta}$ is a vector of parameters. The parameter of interest is $\alpha$. We can then use ordinary least squares to estimate $\boldsymbol{\beta}$ and $\alpha$.

Alternatively, we could start with an economic model. In fact, some simple theories will lead to exactly this equation. Suppose, for example, that the human capital of an individual is a function of her level of schooling. In particular, suppose that the human capital of individual $i$ is given by $h_{i}=s_{i}^{1-\sigma}$, for some parameter $\sigma \in(0,1)$ and $s_{i}$ denotes her level of schooling. She can then earn income equal to $y_{i}=w h_{i}$, where $w$ is the market wage per unit of human capital. In addition, individual $i$ has a cost of schooling given by $\zeta_{i} c_{i} s_{i}$, where $\zeta_{i}$ is an unobserved non-monetary cost component and $c_{i}$ is the monetary cost of schooling for this individual. Suppose that individuals maximize net income, so that individual $i$ will choose schooling to maximize income net of the cost of schooling, that is $w s_{i}^{1-\sigma}-\zeta_{i} c_{i} s_{i}$. After working through the maximization problem, this model implies a relationship identical to the reduced-form equation we started with, but now the parameter $\alpha$ corresponds to $1 / \sigma .^{2}$ Once this equation is derived, estimation is also straightforward and can be performed again by ordinary least squares.

\footnotetext{
${ }^{1}$ See Shadish, Cook and Campbell (2002) on internal and external validity. The notion of external validity, in particular the emphasis on counterfactual exercises, as the defining characteristic of a structural parameter is closely related to Marschak's (1953) definition, which distinguishes between structural parameters that provide "useful knowledge" for understanding the effects of policy within a given sample and/or in new environments. It also clearly presupposes that the empirical strategy has been successful in estimating "causal" effects (for example, as defined in Angrist, Imbens and Rubin (1996).

${ }^{2}$ Specifically, the optimal choice of individual $i$ is $s_{i}=K\left(\zeta_{i} c_{i}\right)^{-1 / \sigma}$, where in this case $K=((1-\sigma) w)^{1 / \sigma}$. After taking $\operatorname{logs}$ and defining $\varepsilon_{i} \equiv-\log \zeta_{i} / \sigma$ and $\alpha=1 / \sigma$, this gives the reduced-form equation above.
} 
Next comes the harder part. We have seen that the same equation can be posited as a reduced-form relationship, or it can be derived from an economic model. But at the end it is the same equation, and it can be estimated in the same manner. So in what sense can we think of it as a "structural relationship"? The answer is related to the notion of external validity introduced above. Suppose we now ask the question: what would be the effects of subsidies to reduce the cost of schooling, $c_{i}$, for a set of individuals? This counterfactual experiment could be motivated by a potential policy that is being contemplated or it may be used for understanding and testing the implications of our theory. The question might be for the same sample on which the initial estimation was performed or it could be for an entirely different sample or population. In either case, one answer to the above question readily follows from using the estimates of $\alpha$ to compute the increase in the years of schooling for individuals whose cost of schooling has declined. But can we trust this answer?

If $\alpha$ is indeed a structural parameter, then we should trust this answer (obviously, subject to standard errors), but not otherwise. ${ }^{3}$ To illustrate what might go wrong when $\alpha$ does not correspond to a structural parameter, imagine, for example, that years of schooling are constrained by school enrollments, which are in turn constrained by the sizes of schools. In this setting, let us further assume that individuals with low cost of schooling get proportionately more of the available school resources (for instance, due to some type of efficient rationing). ${ }^{4}$ In this example, we can still estimate the relationship between $s$ and $c$, and we will obtain a meaningful-looking estimate of $\alpha$. However, the estimate will lack external validity. Consider a policy of expanding the subsidy for schooling to individuals that does not change the constraint that total years of schooling are determined by the sizes of schools. Then the estimate of $\alpha$ from the pre-subsidy regime will not necessarily inform us about the post-subsidy relationship between cost of schooling and years of schooling and will not give us accurate predictions about the impact of the policy.

\footnotetext{
${ }^{3}$ Many empirical equations that do not correspond to structural relationships may nonetheless contain useful information; they just cannot be used for counterfactual policy analysis. We might simply be interested in uncovering correlations, which may help us distinguish between theories, since many relevant theories will have implications about what these correlations should look like. This suggests that it is often useful to estimate reduced-form relationships that do not have structural interpretations, but when doing so, we should be explicit about how they should be (and not be) interpreted.

${ }^{4}$ More specifically, the constraint on school enrollments might imply that total years of schooling should be equal to $\bar{S}$, that is, $\sum_{i} s_{i}=\bar{S}$. Suppose that the economic relationship $s_{i}=K\left(\zeta_{i} c_{i}\right)^{-1 / \sigma}$ still holds at the individual level (i.e., individuals with low cost of schooling get proportionately more of the available school resources). But it must do so with a different value of $K$ than in footnote 2. In particular, the constraint on total schooling implies $K=\bar{S}\left(\sum_{i \in \mathcal{I}}\left(\zeta_{i} c_{i}\right)^{-1 / \sigma}\right)^{-1}$. When the cost of schooling is subsidized, the underlying economic relationship with the new definition of $K$ given here remains unchanged, but the reduced-form relationship captured by our estimating equation above changes (exactly as shown by the above formula for $K$ ).
} 
The problem described here is of course a version of the Lucas critique (Lucas, 1976) that reduced-form form relationships will not be stable in the face of policy interventions. However, the discussion also highlights that this problem is not simply circumvented by deriving the relationship of interest from an economic model, unless this model incorporates the relevant constraints and margins of choice. In the above example, no model that fails to incorporate the constraint on total enrollments will be informative about counterfactuals involving large-scale interventions. Thus, our confidence in the implied answers to policy experiments crucially depends on our confidence in having captured the appropriate structural relationship with the model we are estimating.

How do we convince others and ourselves that our estimates have external validity and can be used for policy analysis or for testing theories? This is where economic theory becomes particularly useful. As a first step, we have to defend, using economic theory, common sense and evidence, that key factors potentially affecting the response to the relevant counterfactual are accounted for, and the model and the functional form we chose indeed capture the salient aspects of the reality ("are a good approximation to reality"). This in turn involves arguing that the functional form is stable over time and across relevant samples, that variation across individuals not captured by the covariates and the cost of schooling can be incorporated into the error term $\varepsilon_{i}$, and that this error term can be modeled as additive and orthogonal to (uncorrelated with) the other variables included in the equation. Using economic theory is often the best way of clarifying whether key factors have been omitted, and whether the underlying assumptions can be defended and provide a good approximation to reality.

However, the previous discussion also highlights that specifying a model that justifies a specific estimating equation is typically not difficult, and may not solve the underlying problem. For example, we saw how we could derive exactly the same estimating equation from a model of individual schooling choice; but if in reality years of schooling are constrained by the sizes of schools, the estimates of $\alpha$ will still not be useful for understanding the implications of a large-scale subsidy for schooling. The problem of course is that for studying the implications of this type of policy, the constraints resulting from the sizes of schools are central, and any model that does not recognize these constraints will not be helpful in such a study. This emphasizes that the proper use of economic theory does not mean writing down of a specific model; instead, it requires that we incorporate the appropriate constraints and margins of adjustments, that we develop the case that economic theory robustly leads to the estimating equation in question, and that we clarify which important economic mechanisms and effects 
are being excluded from the model. ${ }^{5}$

Another advantage of the structural reasoning based on theory is that once we go through the process of explicitly justifying the equation we are estimating, either using economic theory or other theoretical or empirical arguments, we may realize that such an equation cannot easily be defended. In such cases, it has to be interpreted with greater caution, or perhaps it has to be modified or abandoned. This advantage becomes particularly important in contexts where general equilibrium and political economy effects are present. Finally, economic theory provides the best way of interpreting what the estimates from an equation, such as the one we started with, mean. For example, when this equation is derived from the economic model above, we understand that $\alpha=1 / \sigma$ is a function of the elasticity of the human capital production function.

The structural approach also faces major challenges, however. First, as already emphasized, writing down a model like the one described above is clearly not sufficient for achieving external validity. That model itself made several assumptions which are restrictive and may not provide a good approximation to the economic phenomena in which we are interested. This is again illustrated by the above example, which showed that one might end up deriving the same estimating equation from a theoretical model and thus reach the same conclusions about the implications of a counterfactual policy change as one might have done by just specifying a reduced-form equation.

Second, we may in fact question whether there is any ground for assuming a constant elasticity $\alpha$ between years of schooling and costs of schooling. After all, we know that all theories are abstractions and approximations, so there is little reason to believe that a parameter such as $\alpha$ - or the intertemporal elasticity of substitution, or the Frisch elasticity of labor supply, or the elasticity of substitution between two factors, or any other Marschakian preference or technology parameter - should be really constant. But without such constancy, there are severe limits to external validity.

Finally, one may even question the existence or usefulness of "structural parameters" altogether. What we take as a structural parameter for one theory will naturally become an

\footnotetext{
${ }^{5}$ The online appendix discusses some issues that arise in thinking of how we could develop such robust predictions and how we could try to map them to data. This discussion also highlights that in certain cases one could achieve counterfactual validity without much theory. For example, we need only the most basic theory in interpreting a controlled experiment designed to evaluate the effectiveness of a drug. In this case, we can say that common sense and a very limited amount of medical theory are sufficient to interpret the results of the controlled experiment and decide whether they are informative about the effectiveness of the drug in question beyond the experimental setting. It should also be noted that the evaluation of the effectiveness of a drug in this example has a clear parallel to "modeling individual behavior" in economics. As further discussed below, the role of economic theory becomes even more central when our focus shifts to "modeling equilibrium behavior".
} 
endogenous object in another. So a particular model can serve us well as an abstraction for a series of counterfactual experiments, but there will exist other experiments for which it will be much less informative. For example, an elasticity of substitution or certain technology parameters may be constant with respect to certain variations, but would change in response to others. This is almost by necessity: a precondition for external validity is that key factors relevant for the outcome of the counterfactual should be included in the model, and models as abstractions have to exclude several relevant factors, so no single model can include all of the relevant factors for all possible counterfactual exercises.

These challenges notwithstanding, it is clear that we often have to take a position about the parameters being estimated corresponding to structural parameters (at least for a welldefined though perhaps limited set of variations in environment and policy). Otherwise, we will have no way of performing counterfactual exercises and making predictions about policy changes (see Imbens, 2009). But this necessitates a claim to external validity (even if it is only implicit), and economic theory is our best guide for formulating the appropriate models and justifying such claims to external validity. These issues become only more central in the presence of general equilibrium effects and political economy factors, which I turn to next.

\section{The Centrality of General Equilibrium}

The bulk of empirical work using microdata, particularly in development economics, engages in partial equilibrium comparisons. Depending on magnitudes of various effects, general equilibrium interactions can offset or even reverse sensible partial equilibrium conclusions. However, most empirical strategies do not directly estimate general equilibrium effects. ${ }^{6}$

Economic theory nonetheless provides some guidance in assessing the importance of general equilibrium effects. Three types of general equilibrium effects, which are usually not estimated in partial equilibrium comparisons, are potentially important. First, in response to large policy interventions or shocks, imperfect substitution between factors and diminishing returns imply that factor productivities and prices will change. Second, the same policy interventions or shocks can lead to endogenous technology responses. Third, there may be composition effects resulting from equilibrium substitution of some factors or products for others (whereby the composition of micro units changes differently in response to different types of interventions).

\footnotetext{
${ }^{6}$ See also Townsend (2009) for a complementary discussion of the role of general equilibrium analysis in development economics, with special emphasis on credit market issues; Heckman, Lochner and Taber (1998) for a discussion of general equilibrium issues in the analysis of the effects of technology on wage inequality; and Duflo (2004a) for a discussion of other difficulties in "scaling up" policy interventions evaluated using microdata.
} 
Theory generally implies that the first and the third effects will tend to partially offset or even reverse direct partial equilibrium effects, while endogenous technology responses could either dampen or magnify them (see Acemoglu, 2007, for general theoretical results on endogenous technology).

As an example of factor price changes, consider the problem of estimating the returns to schooling. This is typically done by focusing on a small group of individuals who are induced to remain in school for longer and comparing them to other individuals in the same market (thus facing the same prices) who have dropped out of school. The implicit assumption here is that altering schooling decisions will not generate changes in market prices. But for many of the questions relevant for development economics, we wish to think of counterfactuals in which a large fraction of the population acquires more schooling. In this case, it is no longer plausible to assume that prices will necessarily remain constant. Imperfect substitution between different skill levels will typically imply that an increase in the schooling level of a significant fraction of the population may reduce the return to schooling. For example, Angrist (1995) shows that the large school building programs in the Palestinian territories led to a sharp drop in the skill premium.

As an example of endogenous technology responses, consider the large increase in the relative supply of college-educated workers in the United States starting in the late 1960s. Given technology, this change in relative supply should have reduced the college premium. As is well known, the opposite happened in practice, and the college premium increased sharply from the late 1970s onwards. Acemoglu (1998) argues, for example, that this was a consequence of the endogenous response of technology to the relative abundance of more skilled workers. The same reasoning implies that in evaluating the effect of trade opening, one could not simply rely on partial equilibrium estimates derived from firm-level variation in access to foreign markets, since trade opening is a general equilibrium change that will also affect technology choices and the direction of technological change.

As an example of composition effects, consider the problem of estimating the importance of credit market imperfections. Banerjee and Duflo (2005) survey a large body of evidence that small and medium-sized businesses in less-developed economies are credit constrained and an extension of credit to these businesses will make them increase production. Now consider the effect of a large-scale policy of credit expansion to small- and medium-sized businesses. This policy could lead to a different type of composition effect than the one operating in partial equilibrium. For example, it may be the case that in partial equilibrium estimation focusing on firm-level variation we found that firms with better access to credit expanded, but 
this was at the expense of other firms that did not have access to credit (that is, partly by "stealing business" from others). And yet, the same response cannot take place in general equilibrium. As a consequence, when additional credit becomes available to a large fraction of firms, total output may not increase by as much or at all. One could thus imagine a situation in which partial equilibrium estimates of relaxing credit constraints are large, while the general equilibrium effects would be small.

I now further elaborate the first general equilibrium effect, working through endogenous factor prices and diminishing returns, in the context of the effect of life expectancy (and health) on economic growth. A large microeconometric literature shows that healthier individuals are more productive: see, among others, Behrman and Rosenzweig (2004), Schultz (2002), and Straus and Thomas (1998). On this basis, we would expect an increase in the life expectancy of the workforce to lead to greater aggregate productivity. But one should take general equilibrium effects into account, since an increase in life expectancy also increases population, and because of diminishing returns to capital and land, it may decrease labor productivity and may in fact reduce income per capita. How could one investigate whether these general equilibrium effects are important? One approach is to use information from other sources in order to "calibrate" the values of the parameters and then combine this with micro estimates of the effect of health and life expectancy on individual outcomes. ${ }^{7}$ This approach will be successful when we can have confidence in the calibration exercise.

A second approach is to use cross-country variation, even though such variation will be affected by several potentially omitted factors. Acemoglu and Johnson (2007) adopt this approach. They derive the following linear relationship between log life expectancy, $x_{i t}$, and log income per capita, $y_{i t}$, from a neoclassical growth model and the possibility that life expectancy might have a direct positive effect on technology and on human capital:

$$
y_{i t}=\pi x_{i t}+\zeta_{i}+\mu_{t}+\varepsilon_{i t}
$$

The parameter of interest, $\pi$, measures the relationship between log income per capita and log life expectancy. Though this equation can be estimated by ordinary least squares, this is likely to lead to biased estimates of $\pi$, since societies that are successful in solving economic and

\footnotetext{
${ }^{7}$ This is the approach advocated by Banerjee and Duflo (2005) and used by Weil (2007) in the context of health and economic development and by Heckman, Lochner and Taber (1998) in the context of the relationship between technology and wage inequality. Another approach not mentioned in the text, perhaps most promising, is to combine microdata with regional variation to estimate partial and general equilibrium effects simultaneously. This approach is adopted and developed in Acemoglu and Angrist (2000) to estimate human capital externalities exploiting individual-level differences in schooling together with state-wide differences in average schooling (see also Duflo, 2004b, for an application to Indonesian data) and in Acemoglu, Autor and Lyle (2004) to estimate the general equilibrium effects of increased female labor supply (on male and female wages).
} 
institutional problems to achieve higher growth are also likely to provide better public health and other measures that improve life expectancy, and also the increase in income per capita is likely to lead to a mechanical improvement in life expectancy.

To overcome this problem, Acemoglu and Johnson (2007) adopt an instrumental-variables strategy, exploiting global discoveries and diffusion of major drugs, chemicals, and public health technologies. The idea is that these improvements should have raised life expectancy differentially in countries that were subject to different types of initial disease burdens. To implement this idea, they construct a "predicted mortality" variable, $M_{i t}$, based on the 15 most infectious diseases in 1940. They compute the pre-intervention (1940) mortality from each of these 15 diseases in each country. Then, when a global health intervention (technological breakthrough) takes place for a given disease, predicted mortality in each country falls to a different level depending on their pre-intervention mortality from that disease. More specifically, the predicted mortality variable uses a country's initial mortality rate for each of the 15 diseases until there is a global intervention, and after the global intervention, the mortality rate for the disease in question declines to the frontier mortality rate. ${ }^{8}$ Predicted mortality, $M_{i t}$, is then used as an instrument for log life expectancy in the estimation of the relationship between log income per capita and log life expectancy. With this reasoning, the first-stage relationship is

$$
x_{i t}=\psi M_{i t}+\tilde{\zeta}_{i}+\tilde{\mu}_{t}+u_{i t}
$$

For this instrumental-variables approach to be valid, the key exclusion restriction for the estimation strategy is the covariance between the predicted mortality variable, $M_{i t}$, and the error term in the earlier income per capita equation, $\varepsilon_{i t}$, must be zero (i.e., $\left.\operatorname{Cov}\left(M_{i t}, \varepsilon_{i t}\right)=0\right)$. Note that both the second and the first stages (the exclusion restriction) are motivated by theory. The second stage is derived from the neoclassical growth model. The first stage (and thus the exclusion restriction that $\operatorname{Cov}\left(M_{i t}, \varepsilon_{i t}\right)=0$ ) is predicated on the theory that global intervention for a particular disease will affect mortality in a country in proportion with the number of initial deaths from the disease in question in that country, and more importantly, that baseline levels of mortality from different diseases do not have a direct

\footnotetext{
${ }^{8}$ Mathematically, predicted mortality is defined as

$$
M_{i t}=\sum_{d \in \mathcal{D}}\left(\left(1-I_{d t}\right) M_{d i t_{0}}+I_{d t} M_{d F t}\right),
$$

where $M_{d i t}$ denotes mortality in country $i$ from disease $d$ at time $t, I_{d t}$ is a dummy for intervention for disease $d$ at time $t$ (it is equal to 1 for all dates after the intervention), $\mathcal{D}$ denotes the set of the 15 infectious diseases, $M_{d i t_{0}}$ refers to the pre-intervention (1940) mortality from disease $d$ in the same units, and $M_{d F t}$ is the mortality rate from disease $d$ at the health frontier of the world at time $t$.
} 
effect on future income beyond their effect working through future life expectancy and health conditions. Acemoglu and Johnson (2007) provide evidence consistent with this exclusion restriction. For example, prior to 1940 predicted mortality does not predict future income or population growth, which is consistent with the notion that past levels of life expectancy do not have a direct effect on future growth. The online appendix discusses why the specific instrumental-variables strategy suggested here is only valid with certain formulations of the second-stage equation, and different theories for the relationship between health and growth, encapsulated in different second-stage relationships, may not be consistent with the same exclusion restriction, thus further emphasizing the role of theory in guiding the estimation strategy.

The surprising finding in Acemoglu and Johnson (2007) is this that despite the wellestablished positive micro estimates of the effect of health on productivity, in general equilibrium the effect on income per capita appears to be negative. This result probably arises because the improvements in life expectancy were associated with very large increases in population. While this conclusion comes with several caveats, not least because the negative estimates are often quite large and come from a specific episode (during which mortality rates may have declined unusually rapidly relative to morbidity rates), it illustrates the possibility that general equilibrium empirical conclusions can be quite different from partial equilibrium ones. ${ }^{9}$ It reiterates the importance of incorporating general equilibrium considerations for conducting counterfactual exercises concerning the effects of large changes in variables such as schooling, health conditions or access to credit on income per capita or other aspects of economic development.

\section{No Development without Political Economy}

There is increasing recognition that institutional and political economy factors are central to economic development. Many problems of development result from barriers to the adoption of new technologies, lack of property rights over land, labor and businesses, and policies distorting prices and incentives. These institutions and policies are not in place exclusively, or even primarily, because of a lack of understanding of economic principles on the part of policymakers. Typically, policymakers introduce or maintain such policies to remain in power, or to enrich themselves, or because politically powerful elites oppose the entry of rivals, the introduction of

\footnotetext{
${ }^{9}$ The conclusions may also depend on the fact that Acemoglu and Johnson (2007) focus on changes in health largely (though not solely) associated with mortality. Bleakley (2007), focusing on changes related to morbidity, obtains different results.
} 
new technologies, or improvements in the property rights of their workers or competitors (for example, Acemoglu, Johnson and Robinson, 2005a). But this perspective implies that theory again becomes particularly important in evaluating (or framing) possible effects of large-scale policy interventions; counterfactual analyses that ignore political economy factors, like those that do not take account of general equilibrium effects, may give misleading answers. In this case, convincing micro or even macro (general equilibrium) evidence about the effects of a particular policy change on economic outcomes is not in itself sufficient to gauge what the implications will be when such a policy is encouraged or implemented.

The experience of Ghana with exchange rate policy under Prime Minister Kofi Busia in 1971 provides a sharp illustration. Busia pursued expansionary economic policies after coming to power in 1969, and maintained various price controls and an overvalued exchange rate. But Ghana was soon suffering from a series of balance of payments crises and foreign exchange shortages. Faced with these crises, Busia signed an agreement with the IMF on December 27, 1971, which included a massive devaluation of the currency. A few days following the announcement of the devaluation, Busia was overthrown by the military led by Lt. Col. Acheampong, who immediately reversed the devaluation (see, for example, Herbst, 1993; Boafo-Arthur, 1999). There was little doubt that devaluation was good economics in Ghana. But it was not good politics. State controls over prices, wages, marketing boards and exchange rates were an important part of the patronage network, and any politician who lost the support of this network was susceptible both at the polls and against the military. Busia suffered this fate.

This episode illustrates a general point: When political economy factors are important, evidence on the economic effects of large-scale policy changes under a given set of political conditions is not sufficient to forecast their effect on the economy and society. This principle does not just apply to exchange rate policy. For example, the fact that increasing availability of credit to firms would increase aggregate output given all other policies does not imply that an actual reform of the credit market will necessarily work. Consistent with this perspective, Haber and Perotti (2008) argue and provide evidence that limiting access to finance is a powerful tool in the hands of political and economic elites for restricting entry into lucrative businesses. Thus, reforms of credit markets will often face political opposition from powerful parties, and even when they are implemented, this implementation may be imperfect or accompanied by other policies aimed at nullifying the effects of the reform. This type of endogenous policy response undermining the objectives of a reform is termed the seesaw effect in Acemoglu, Johnson, Robinson and Querubín (2008), who provide evidence that the reforms aimed at reducing inflation by granting independence to the central bank typically do not work 
in societies with weak institutions and sometimes trigger other policy responses - for example, larger government deficits - to undo the reduction in the ability of the government to provide favors to politically powerful groups.

There are many parallels between the implications of general equilibrium effects for the interpretation (and extrapolation) of partial equilibrium estimates discussed in the previous section and the implications of political economy factors. Even though in general we have less of an understanding of the channels of influence of political economy, a general principle provides a useful starting point: large-scale shocks and policy interventions will create political economy responses from those who see their economic or political rents threatened or from those that see new options to increase these rents. Such responses are the basis of all three examples mentioned so far: the overthrow of Busia, potential obstacles to credit market reform, and the seesaw effect. The difficulty lies in the fact that which groups and individuals will be able to mobilize and respond to these changes will vary across different applications.

How should empirical research in economic development take political economy into account? A first step would be to use empirical work to understand better the role of political economy factors in development. This type of research on empirical political economy of development is relatively new. The first generation of work focused on cross-country variation (see the overview in Acemoglu, Johnson and Robinson, 2005a). Although research in this area is expanding, given the importance of political economy for the problems of development, it remains surprising how few papers investigate important political economy channels using microdata and careful empirical strategies. I now discuss a few of these papers to give a sense of what approaches are available.

Low agricultural productivity throughout the developing world is a major problem, and also a puzzle. In many instances, "fallowing," plowing the land but leaving it unseeded for a period of time so as to reduce weed growth and conserve soil moisture, would increase productivity considerably. Goldstein and Udry (2008) document that in southern Ghana the amount of fallowing is massively insufficient. A non-political economy answer would be to encourage fallowing. But in reality, this recommendation (or policy) would be incorrect or at least seriously incomplete, because Goldstein and Udry show that fallowing increases the risk of confiscation of land by powerful chiefs and other connected individuals. In fact, those with sufficient political power, who presumably face a lower risk of confiscation, choose significantly higher levels of fallowing. This finding illustrates both the importance of secure property rights and the role of political economy constraints on productive investments. It also highlights the role of local power structures in villages in shaping the security of property rights and incentives 
for investment.

More work is needed on understanding how the political economy context is shaped. An emerging literature investigates these issues using microdata. As one example, Ferraz and Finan (2008) use audit reports from an anti-corruption program in Brazil to estimate the effect of electoral accountability on corruption and misappropriation of funds by politicians. They find that mayors who cannot get reelected because of term limits are significantly more corrupt and misappropriate 27 percent more resources than mayors with reelection incentives. They also show that, consistent with theory, these effects are stronger when voters have access to less information and when judicial punishment against corruption is weaker. In a related paper, Ferraz and Finan (2009) study the effects of politician salaries on politician behavior and quality of public services. They exploit a discontinuity in the salaries of local politicians across Brazilian municipalities resulting from a constitutional amendment imposing salary caps depending on the size of municipal population. Using regression discontinuity techniques, they find that greater salaries are associated with greater competition among potential candidates, and moreover that the quality of the elected legislatures measured by education or experience improves. Higher salaries are also associated with improvements in various dimensions of politician performance. ${ }^{10}$

Another approach is to assess the extent to which past historical institutions have long-run effects. Acemoglu, Johnson and Robinson (2005a) summarize several cross-country studies suggesting that certain major events such as the foundation of colonial institutions or the separation of the Koreas can have persistent effects. However, controlling for confounding factors is often difficult in cross-country studies and the exact mechanism leading to persistent effects is often difficult or impossible to pinpoint. Recent work by Dell (2009) focuses on the potential effects of the forced labor system used by the Spanish colonial government in Peru and Bolivia. This system, which forced a large fraction of the adult male population of villages near the Potosi silver and Huancavelica mercury mines to work in these mines, was used extensively in the sixteenth century, and was abolished in 1812. Those inside and outside the boundary of the catchment area of the forced labor program were subject to different labor regulations. In a regression discontinuity design, Dell finds that areas subjected to forced labor more than 200 years ago now have about one-third lower household equivalent consumption. The available data also allow an investigation of some potential mechanisms for this very large

\footnotetext{
${ }^{10}$ Returning to the contrast between different counterfactual exercises, one might question, for example, whether this regression discontinuity estimate would be informative about the effects of a large-scale increase in politician salaries, which might cause different composition effects than cross-municipality variation in salaries induced by salary caps.
} 
and persistent effect, which appears to be related to lack of public goods in areas subject to forced labor. This lack of public goods in turn may be related to the policies of the Spanish governments to limit competition for labor in the catchment areas from private landholders and businesses.

Finally, again related to the issue of coercion, Naidu and Yuchtman (2009) investigate how the ability of employers to imprison or fine an employee for breach of contract under the Master and Servant Acts, which remained in effect in Britain until 1875, affected labor market relations. They provide evidence that employers made extensive use of their coercive ability under the law, and as a consequence, labor demand shocks were largely met by using increased persecutions for contract breach rather than higher wages. This finding is consistent with theoretical predictions of recent models of labor coercion such as Acemoglu and Wolitzky (2009).

Overall, the above-mentioned papers, though distinct in methodology and scope, show how microdata and regional variation in institutions and laws can shed light on the role of political economy factors in development. Empirical work in development economics should pay more attention to, and build a more systematic understanding of, political economy. It must also study how different counterfactual and policy experiments will interact with or be resisted by political factors.

\section{Concluding Remarks}

A key objective of empirical work in development economics is to discriminate between theories about the causes of economic growth and to conduct counterfactual analysis to build a systematic understanding of how an economy will respond to large changes in factor supplies, technology or policy. Economic theory is central in this endeavor. In fact, economic theory becomes more important in the presence of general equilibrium and political economy considerations.

General equilibrium and political economy effects are often difficult to estimate or to quantify. However, they are pervasive and essential for important questions in development economics. Most research in economics has (and should have) a narrow focus and tries to investigate a particular set of factors in a specific context. But in development economics where the agenda ought to be broad, we should also not lose sight of the bigger picture of the problem of economic development. This implies that we should strive to incorporate general equilibrium and political economy effects when we can, and we should be cognizant of their importance 
when we cannot.

It is also useful to note that general equilibrium and political economy considerations are not only a constraint in policy analysis, even though I focused on cases in which these considerations tend to offset or reverse partial equilibrium effects. For example, the endogeneity of political economy responses also implies that certain economic policies and shocks might have more beneficial effects than what the pure economic analysis would suggest, because they can lead to a beneficial change in the political equilibrium. One such example, discussed in Acemoglu, Johnson and Robinson (2005b), is the possibility that Atlantic trade may have had long-run beneficial effects in Europe mainly by changing the political equilibrium in several countries towards more participatory regimes.

\section{Acknowledgments}

I thank Joshua Angrist, David Autor, Abhijit Banerjee, Timothy Besley, Angus Deaton, Melissa Dell, Esther Duflo, Fred Finan, Chad Jones, Guido Imbens, Ariel Pakes, James Robinson, Timothy Taylor, Robert Townsend, Chris Udry, and Eric Weese for useful comments and suggestions.

\section{References}

Acemoglu, Daron (2002). "Directed Technical Change" Review of Economic Studies, 69 (October): 781-810.

Acemoglu, Daron (2007). "Equilibrium Bias of Technology" Econometrica, 75 (September): 1371-1410.

Acemoglu, Daron (2009). Introduction to Modern Economic Growth, Princeton University Press, Princeton.

Acemoglu, Daron and Josh D. Angrist (2000). "How Large are Human Capital Externalities? Evidence from Compulsory Schooling Laws." NBER Macroeconomics Annual 2000. MIT Press, Cambridge: 9-59.

Acemoglu, Daron, David H. Autor and David Lyle (2004). "Women, War and Wages: The Effect of Female Labor Supply on Labor Market Outcomes." Journal of Political Economy, 112 (June): 497-551.

Acemoglu, Daron and Simon Johnson (2007). "Disease and Development: The Effect of Life Expectancy on Economic Growth.” Journal of Political Economy, 115 (December): 925985. 
Acemoglu, Daron, Simon Johnson and James A. Robinson (2005a). "Institutions as a Fundamental Cause of Long-Run Growth." In Philippe Aghion and Steven Durlauf (editors) Handbook of Economic Growth, North Holland, Amsterdam: 384-473.

Acemoglu, Daron, Simon Johnson and James Robinson (2005b). "The Rise of Europe: Atlantic Trade, Institutional Change and Growth." American Economic Review, 95, pp. 546579.

Acemoglu, Daron, Simon Johnson, James A. Robinson and Pablo Querubín (2008). "When Does Policy Reform Work? The Case of Central Bank Independence." Brookings Papers on Economic Activity.

Acemoglu, Daron and Alex Wolitzky (2009). "The Economics of Labor Coercion." MIT mimeo.

Angrist, Joshua D. (1995). "The Economic Returns to Schooling in the West Bank and Gaza Strip." American Economic Review, 85 (December): 1065-1087.

Angrist, Joshua D., Guido W. Imbens, and Donald B. Rubin (1996). "Identification of Causal Effects Using Instrumental Variables." Journal of the American Statistical Association, 91 (June): 444-455.

Banerjee, Abhijit V. and Esther Duflo (2005) "Economic Growth through the Lenses of Development Economics." In Philippe Aghion and Steven Durlauf (editors) Handbook of Economic Growth, North Holland, Amsterdam: 384-473.

Behrman, Jere R. and Mark R. Rosenzweig (2004). "The Returns to Birthweight." Review of Economics and Statistics 86 (May): 586-601.

Bleakley, Hoyt (2007). "Disease and Development: Evidence from Hookworm Eradication in the American South." Quarterly Journal of Economics, 122 (February): 73-117.

Boafo-Arthur, K. (1999). "Ghana: Structural Adjustment, Democratization and the Politics of Continuity." African Studies Review, 42 (2): 41-72.

Dell, Melissa (2009). "The Persistent Effects of Peru's Mining Mita." MIT mimeo.

Duflo, Esther (2004a). "Scaling up and Evaluation." MIT mimeo.

Duflo, Esther (2004b) "Medium Run Effects of Educational Expansion: Evidence from a Large School Construction Program in Indonesia." Journal of Development Economics, 74: 163-197.

Ferraz, Claudio and Frederico Finan (2008). "Electoral Accountability and Corruption: Evidence from the Audits of Local Governments." UCLA mimeo.

Ferraz, Claudio and Frederico Finan (2009). "Motivating Politicians: The Impacts of Monetary Incentives on Quality and Performance." NBER Working Paper. 
Goldstein, Markus and Christopher Udry (2008). "The Profits of Power: Land Rights and Agricultural Investment in Ghana." Journal of Political Economy, 116 (December): 981-1022.

Haber, Steve and Enrico Perotti (2008). "Political Economy of Finance." Forthcoming Journal of Economic Literature.

Heckman, James J., Lance Lochner, and Christopher Taber (1998). "Explaining Rising Wage Inequality: Explorations with a Dynamic General Equilibrium Model of Labor Earnings with Heterogeneous Agents." Review of Economic Dynamics, 1 (January): 1-58.

Herbst, Jeffrey (1993). The Politics of Reform in Ghana, 1982-1991. University of California Press, Berkeley and Los Angeles.

Imbens, Guido (2009). "Better LATE Than Nothing: some comments on Deaton (2009) and Heckman and Urzua (2009)." Harvard, mimeo.

Lucas, Robert E. (1976). "Economic Policy Evaluation: A Critique." in Karl Brunner and Alan H. Meltzer (editors) The Phillips Curve and Labor Markets press F4, North Holland, Amsterdam, 19-46.

Marschak, Jacob (1953). "Economic Measurement for Policy and Prediction." In W. Hood and T. J. Koopmans (editors) Studies in Econometric Method, Wiley, New York: 1-26.

Naidu, Suresh and Noam Yuchtman (2009). "How Green Was My Valley? Coercive Contract Enforcement in 19th Century Industrial Britain," Harvard University mimeo.

Schultz, T. Paul (2002). "Wage Gains Associated with Height as a Form of Health Human Capital." American Economic Review, 92 (May): 349-353.

Shadish, William H., Thomas D. Cook and Donald T. Campbell (2002). Experimental and Quasi-Experimental Designs for Generalized Causal Inference, Houghton Mifflin, Boston.

Soares, Rodrigo R. (2005). "Mortality Reductions, Educational Attainment and Fertility Choice." American Economic Review, 95 (July): 780-795.

Strauss, John and Duncan Thomas (1998). "Health, Nutrition and Economic Development." Journal of Economic Literature, 36 (June): 766-817.

Townsend, Robert (1994). "Risk and Insurance in Village India." Econometrica, 62 (May): 539-591.

Townsend, Robert (2009). "Financial Structure and Economic Welfare: Applied General Equilibrium Development Economics." MIT mimeo.

Weil, David N. (2007). "Accounting for the Effect of Health on Growth." Quarterly Journal of Economics, 122 (August): 1265-1306. 


\section{Appendix (Not for Publication)}

\section{The Role of Theory in Instrumental-Variables Strategies}

In this appendix, I illustrate the role of theory further using the same example from Acemoglu and Johnson (2007) used in the text. The estimating equation for income per capita can be alternatively written as

$$
\Delta y_{i}=\pi \Delta x_{i}+\Delta \mu+\Delta \varepsilon_{i}
$$

where $\Delta$ denotes the difference between dates $t_{0}$ and $t_{1}$ (for example, in Acemoglu and Johnson's estimation 1940 and 1980 or 2000). Estimating this differenced equation would (mechanically) lead to identical results to those obtained from the estimation of the level equation for income per capita presented in the text. However, the literature on the cross-country relationship between health and income sometimes estimates equations of the form

$$
\Delta y_{i}=\alpha y_{i t_{0}}+\beta x_{i t_{0}}+\pi \Delta x_{i}+\Delta \mu+\Delta \varepsilon_{i}
$$

where $x_{i t_{0}}$ is the initial (1940) level of log life expectancy and $y_{i t_{0}}$ is the initial (1940) level of income per capita. It may then be tempting to estimate this modified model using a similar IV strategy, in particular, using the same predicted mortality variable (either by treating the initial levels $x_{i t_{0}}$ and $y_{i t_{0}}$ as exogenous or by instrumenting for them using their lagged values or geographic controls). The reasoning would be that if predicted mortality is a good instrument for our original estimation exercise, then it must be a good instrument for estimating this modified model. But this reasoning is incorrect.

As already noted in the text, we need both the second and the first stages to be derived from appropriate (and logically consistent) economic models. The second stage in Acemoglu and Johnson was derived from the neoclassical growth model. A second stage equation such as the one in this modified model, with initial life expectancy on the right-hand side, could also be derived from theory, for example, from one where life expectancy in 1940 would have had a direct effect on productivity in 1980 or 2000 (40 or 60 years thereafter). However, the estimation strategy additionally requires a theoretical justification for the first stage, or the exclusion restriction (embedded in the assumption above that $\left.\operatorname{Cov}\left(M_{i t}, \varepsilon_{i t}\right)=0\right)$. As highlighted above, this exclusion restriction could only make sense if the baseline level of mortality does not have a direct effect on future growth. If it did, the assumption that $\operatorname{Cov}\left(M_{i t}, \varepsilon_{i t}\right)=0$ would be directly violated. ${ }^{11}$ But this implies that the theoretical argument underlying the exclusion

\footnotetext{
${ }^{11}$ This may or may not be a valid assumption in general. As noted in the text, Acemoglu and Johnson provide evidence to substantiate this assumption and increase the plausibility of this exclusion restriction.
} 
restriction cannot be logically combined with a model that takes the form of this modified equation, even though it is entirely consistent with the original model we started with. We thus have a simple example where one needs to consider the theoretical foundations of the entire set of economic relations (or more explicitly, the first and second stages) together in order not to make logical errors.

The broader point is that one cannot think of "instruments" without theory. What makes a particular variable a valid instrument is a robust theoretical justification for the entire set of economic relationships being estimated, that is, both the specification of the structural parameters and the corresponding first stages and exclusion restrictions. When either of these changes, the validity of the instrument may be jeopardized. This, of course, should not be surprising in view of the discussion we started with: the plausibility of structural parameters, and thus their estimation, crucially depends on using economic theory to derive an "appropriate" model as the building block for estimation. In this light, it should be clear that there cannot be "instruments" without theory.

\section{Conversation Between Theory and Econometrics}

The text emphasized the importance of economic theory in helping us specify empirical models with some degree of counterfactual validity. In this Appendix, I briefly discuss some issues that arise in attempts to implement this. Economic theory is based on mathematical models that are abstractions of reality. Our models involve several assumptions, many of which are adopted for convenience or as "simplifying" assumptions. With all of its assumptions, a model implies a set of relationships between different variables. But we may not necessarily wish to take all of these relationships as empirical predictions to be tested or used for counterfactual analysis. I now suggest that we ought to distinguish between the key implications and auxiliary implications of models, though in practice we often fail to do so.

Let us think of a model as a mapping from assumptions into empirical relationships. For concreteness, let us think of these empirical relationships as moments in the data (e.g., the conditional covariance of one variable with another), and focus on a specific problem: the relationship between income distribution, credit markets and occupational choice, for example, studied by Banerjee and Newman (1993). Let $\mathcal{A}$ denote the set of assumptions that one could make in modeling this problem. An element $A \in \mathcal{A}$ corresponds to a set of assumptions, that is, such things as the exact specification of production functions, the parameterization of the joint distribution of talent and initial wealth, the intertemporal preferences of agents, assumptions 
concerning how the credit market works, and assumptions on conjectures, expectations and the equilibrium concept. Since $A$ is an instance of a complete set of assumptions for the problem at hand, we can think of this as a "model". This model $A$ then generates some empirical implications. I will summarize these by a set of moments, denoted by $M \in \mathcal{M}$, which could include the correlations between the interest rate, the occupational distribution, productivity and initial wealth. Economic theory then amounts to using these assumptions in order to derive empirical relationships, or sets of moment conditions. Thus we can think of economic theory as a mapping (correspondence) $f: \mathcal{A} \rightrightarrows \mathcal{M}$, specifying which set of moments we should expect in the data for a set of assumptions.

The difficulty here is twofold. First, in writing down a model $A \in \mathcal{A}$, most theorists, rightly, will go for a minimalist structure. In many instances, $A$ will not even contain any stochastic elements. For example, Banerjee and Newman's model leads to a unique nonstochastic equilibrium for most parameter values, where the initial distribution of wealth together with an individual's wealth determines his and his dynasty's occupational choices. To generate moment conditions that would correspond to correlations in the data, one would then have to add an unmodeled error term. Although one could interpret this error term as coming from "measurement error," this is clearly not a satisfactory interpretation, since there are many other factors relevant for occupational choices not captured by the model at hand, and they will all be subsumed into this error term, though they are not in reality related to measurement error. Yet this is not a shortcoming, but rather a strength of the model. Banerjee and Newman's model is successful largely because it abstracts from several features of the world. Second, for the same reasons of parsimony and simplicity, a model typically involves assumptions that are "auxiliary," meaning that they are made for convenience, and in the hope that they are not the source of its "main" conclusions. Naturally, what these main conclusions are is not always a simple matter to determine.

This issue notwithstanding, the central difficulty here is that the set of moment implications $M$ depends on the entire set of assumptions, $A$. Suppose, for example, that $A=A^{\prime} \cup A^{\prime \prime}$, where $A^{\prime}$ and $A^{\prime \prime}$ are two disjoint sets of assumptions, and those in the set $A^{\prime}$ correspond to the "key" assumptions, while $A^{\prime \prime}$ contains the auxiliary and simplifying assumptions. For example, in Banerjee and Newman, the assumption that all individuals have the same ability in all occupations, that there is no intensive margin of production, and that dynastic saving decisions are "myopic" are auxiliary assumptions. These assumptions, taken together, lead to a set of predictions. For example, taken naïvely, the model implies that there will exist a threshold level of wealth, such that all dynasties with initial wealth below this level will remain in subsistence 
or become workers, whereas those just above this threshold will become entrepreneurs. If we were to take such an assumption seriously, it would lead to the rejection of the model, but this would not be an insightful rejection. Instead, the Banerjee and Newman model is insightful because it highlights how the credit market problems create a link between wealth and occupational choice, and how this link depends on factor prices, which are themselves endogenously determined by the entire distribution of income.

This discussion highlights two problems. First, the insights from certain models may be "conceptual" and thus difficult to translate into moment conditions. For example, the insight that income distribution matters for occupational choices of an individual (with a given income level) is a conceptual point, even though one could devise tests by comparing different economies or the same economy over time in order to investigate the degree to which such a link is present. Second, not all of the implications of the model should be taken seriously. The second problem suggests that we may wish to separate the set of moment conditions, $M$, into two disjoint sets, $M=M^{\prime} \cup M^{\prime \prime}$, so that $M^{\prime}$ corresponds to the set of "robust" moment predictions, which we should test or use as guidance for empirical work, whereas $M^{\prime \prime}$ corresponds to the moment conditions generated by the "auxiliary" assumptions. However, such a separation is not typically possible, since each moment implication of the model is potentially generated by all of the assumptions taken together. In the Banerjee and Newman model, for example, we cannot simply remove the assumptions regarding the form of the production function and still obtain moment conditions about the relationship between occupation and wealth.

This discussion suggests that in formulating economic theories which we wish to apply to data (either by ourselves or by others), we should pay special attention to which dimensions of the model are introduced just for achieving tractability and parsimony (the so-called "auxiliary") assumptions, and which assumptions and implications of the model are "robust" and should be relied upon and used empirically (or conceptually). Unfortunately, we do not have the theoretical and econometric tools to achieve this, ${ }^{12}$ and developing such tools, or at the very least, trying to emphasize in specific instances which predictions are more robust, would be a useful direction for future research. In addition, even though such tools are not currently available, in specific instances, considerable progress is possible. I will now illustrate this using a recent paper by Weese (2009).

Weese (2009) studies the mergers across Japanese municipalities. Changes in Japanese

\footnotetext{
${ }^{12} \mathrm{On}$ the theory side, the literature on robust comparative statics, which provides qualitative predictions for a range of models, might be one useful direction. Such robust comparative statics can be obtained for environments that can be represented as supermodular games (Milgrom and Roberts, 1994, Vives, 1990) or for those that can be represented as aggregative games (Acemoglu and Jensen, 2009).
} 
government policy on municipality finance in 1995 led to major changes in municipality structure. Many small Japanese municipalities that did not previously have incentives to merge, because this would have reduced the transfers they received from the central government, were induced to merge after this change in policy and the number of municipalities declined from 3232 to 1800. Mergers across municipalities are important for public finance (because they determine the type and amount of local public goods), for development economics (since there are marked inequalities across municipalities in terms of income and provision of public goods, e.g., Acemoglu and Dell, 2010), and for political economy (as they are a major example of endogenous coalition formation). Weese is interested in estimating the "preferences" of different municipalities concerning mergers, and whether given these preferences, a better policy could have been devised. This type of counterfactual exercise clearly requires structural parameters in which we can have some confidence. Thus this exercise must start with a theoretical model, which will then be estimated to obtain structural parameters to use for the counterfactual and policy analysis.

One line of attack would be to specify a dynamic or static game of coalition formation, with specific assumptions on the game form. But these specific assumptions will translate into different predictions on which coalitions will form (which mergers will take place). Thus using a specific model, one could typically obtain significantly different predictions then using another related model, and structural estimation of each of these models is likely to lead to very different conclusions because auxiliary assumptions, such as those related to the order in which offers are made and how different equilibria are selected, will impact implications and inference. ${ }^{13}$ Instead, Weese adopts a different approach, more in line with the type of conversation between theory and empirics suggested here: he specifies a general hedonic coalitional game, where municipality preferences depend on a few characteristics (average income, distance, etc.), and given these preferences he focuses on the Von Neumann-Morgenstern stable set. ${ }^{14}$ This set is not a singleton, thus the model, equipped with this equilibrium/solution concept, does not make a unique prediction. Nevertheless, it rules out a large set of mergers given underlying preferences, and thus specifies a set of moment conditions that can be used for estimation. Crucially, these are not all of the moment conditions that will follow from a model that would make additional auxiliary assumptions to specify, say, a unique equilibrium merger structure

\footnotetext{
${ }^{13}$ Acemoglu, Egorov and Sonin (2009) consider a class of dynamic coalition formation games, where "auxiliary" assumptions, for example, those concerning the order in which offers are made and acceptance and voting procedures, do not affect the set of predictions. This provides another example of a strategy to obtain "robust implications," even though such results can only be obtained under certain, somewhat restrictive, assumptions.

${ }^{14}$ See, among others, Pakes (2008) and Tamer (2003), for different approaches to the estimation of models with multiple equilibria.
} 
for every value of the underlying parameter vector. Interestingly, in this case, Weese is able to estimate the underlying preferences and conduct counterfactual policy analysis. ${ }^{15}$ His estimates show that a different government policy would have led to better (merger) outcomes, and that, somewhat surprisingly, allowing side transfers would have disadvantaged poor municipalities (because their willingness to merge with richer municipalities would have given the latter significant bargaining power).

Overall, one important direction for applied theory work (in economics in general and in development economics) would be to carefully delineate which sets of predictions are more robust, and thus (policy) invariant to auxiliary assumptions, and develop empirical strategies and methods of conducting counterfactual experiments that exploit these more robust implications. In the meantime, this discussion also highlights that if structural estimation relies on all of the moment conditions implied by a (simple) model, this may lead to misleading results. Making good use of theory does not mean taking all of the predictions of a model seriously, but to make use of the key and robust implications from theoretical models to specify and estimate structural parameters. It thus also requires us to be cognizant of which dimensions of a model are adopted just for simplicity, tractability and convenience.

\section{Additional References}

Acemoglu, Daron and Melissa Dell (2010). "Productivity Differences between and within Countries." Forthcoming American Economic Journal: Macroeconomics.

Acemoglu, Daron, Georgy Egorov and Konstantin Sonin (2009). "Dynamics and Stability of Constitutions, Coalitions and Clubs." NBER working paper \# 14239.

Acemoglu, Daron and Martin Kaee Jensen (2009). "Aggregate Comparative Statics," MIT, working paper.

Banerjee, Abhijit V. and Andrew Newman (1993). "Occupational Choice and the Process of Development." Journal of Political Economy, 101 (February): 274-298.

Milgrom, Paul and John Roberts (1994). "Comparing Equilibria." American Economic Review, 84 (March): 441-459.

Tamer, Elie (2003). "Incomplete Simultaneous Discrete Response Model with Multiple Equilibria." Review of Economic Studies, 70 (January): 147-165.

Townsend, Robert (1994). "Risk and Insurance in Village India." Econometrica, 62 (May):

\footnotetext{
${ }^{15}$ For example, one estimation strategy is to assign uniform probabilities to all coalition structures in the Von Neumann-Morgenstern set and then to estimate the underlying parameters by quasi-maximum likelihood.
} 
539-591.

Townsend, Robert (2009). "Financial Structure and Economic Welfare: Applied General Equilibrium Development Economics." MIT mimeo.

Weese, Eric (2009). "Political Mergers As Coalition Formation: Evidence from Japanese Municipal Mergers." Yale University mimeo.

Vives, Xavier (1990). "Nash Equilibrium with Strategic Complementarities" Journal of Mathematical Economics, 19: 305-321. 